\title{
ÉTICA, PESQUISA E ANÁLISE DO DISCURSO*
}

\author{
Bethania Mariani**
}

\begin{abstract}
Resumo
Este texto abre uma discussão sobre o conceito de ética, sua interface com a pesquisa lingüística e, mais especificamente, com o quadro teórico-metodológico da Análise do Discurso.

Certas palavras eruditas, há muito confinadas aos dicionários e à prosa acadêmica, têm a sorte, ou o azar-um pouco como uma solteirona resignada que se torna, sem compreender por quê, a coqueluche de um salão -, de sairem subitamente ao ar livre, de serem plebiscitadas e publicitadas, impressas, televisadas, mencionadas até nos discursos governamentais. A palavra ética, que tão fortemente sabe a grego, a curso de filosofia, que evoca Aristóteles (Ética a Nicômaco, um best-seller famoso!), encontrase hoje sob a luz dos holofotes.
\end{abstract}

A. Badiou

\section{Situando o ponto}

O tema proposto para essa mesa - ética na pesquisa lingüística - trouxe-me à memória o passado recente de nossa história brasileira que foi um acentuado interesse, e conseqüente divulgação na mídia, do tema da ética. Muito se falou e muito se debateu sobre a (falta de) ética, sobretudo no âmbito das formas de agir do poder público, por

- Esse texto foi apresentado na mesa-redonda Ética em pesquisa lingiǘstica, durante o III SELIN, organizado pela UNESP de S. José do Rio Preto, SP, em outubro de 2003.

"UFF, Brasil.

Rua, Campinas, 10:9-22, 2004 
um lado, e no papel dos meios de comunicação em fazer vigorar preceitos éticos, por outro. Em nome da ética desqualificou-se a política, sem dúvida, mas também o político, enquanto lugar próprio das diferenças e das disputas entre as forças sociais.

No entanto, e concordando com o que alguns pesquisadores em ciências humanas já ressaltaram,' tal proliferação de discursos sobre a ética é significativa de uma certa ambigüidade: esse excesso discursivo talvez represente um esvaziamento dos sentidos ao mesmo tempo em que apresenta uma pressuposição de um sentido único e já-sabido de todos. Perde-se de vista uma discussão político-social propriamente dita das relações e das diferenças entre ética e moral, o que acaba produzindo como efeito uma noção de ética com conteúdo moralizante, ou seja, enquanto modelo idealizado a ser seguido de certas condutas sociais. ${ }^{2}$

Possivelmente, essa falta de debate aponta para uma outra forma histórica de se lidar com a questão, ou não. Seja como for, principalmente no âmbito desse trabalho - que traz a análise do discurso e a pesquisa em lingüística -, uma discussão sobre conceitos e sua aplicabilidade a um determinado campo de questões precisa estar circunscrita teoricamente para que não se caia em generalismos ou dogmatismos.

Assim sendo, discutir a questão da ética em pesquisa lingüística supõe construir um recorte desse tema de modo a permitir, por um lado, discorrer sobre o que se entende por ética e seus sentidos, em termos específicos, para, por outro, formular questões pertinentes à pesquisa no campo das ciências da linguagem. A construção de tal recorte, por sua vez, supõe que se explicite o lugar de onde isso será feito, pois, como se sabe, o lugar de onde se fala constitui o dizer.

Assim sendo, antes de mais nada, é preciso dizer que o recorte realizado sobre esse tema tem sua base teórica a partir das colocações feitas pela Análise do Discurso, uma disciplina que se constitui no entremeio da lingüística, da psicanálise, do materialismo histórico, e que visa, entre outras coisas, à compreensão dos gestos de interpretação constitutivos dos processos históricos da produção de sentidos.

\footnotetext{
'R. Paiva, 2002.

${ }^{2}$ Por exemplo, com forte influência da mídia que faz vigorar a ética dos direitos humanos, circula como pressuposto inegável que mulheres, idosos, negros e crianças, pobres ou não, são sempre vítimas sociais em potencial.

Rua, Campinas, 10: 9-22, 2004
} 
Trazer a Análise do Discurso como lugar de sustentação para uma discussão sobre a ética na pesquisa em linguagem é fundamental na medida em que se trata de uma disciplina crítica aos exageros interpretativos realizados a partir de leituras subjetivas ou por leituras a-históricas. Em outras palavras, a Análise do Discurso não realiza uma leitura subjetiva, ou seja, aquela na qual o leitor busca conteúdos e projeta no texto categorias de análise que não passam por nenhum tipo de filtro crítico. Da mesma maneira, a Análise do Discurso não pratica leituras des-historicizadas, nas quais reduzse o texto a uma rede de nexos coesivos e argumentativos. Afinal, como diz Pêcheux, "em face das interpretações sem margens nas quais o intérprete se coloca como um ponto absoluto, sem outro nem real, trata-se aí de uma questão de ética e política: uma questão de responsabilidade". 3

Se, para a Análise do Discurso, considera-se que tanto os processos de produção de sentidos quanto a própria análise desses processos são regulados por sua inserção na história, pode-se afirmar, então, que em sua própria constituição a questão ética já se coloca. E já se coloca porque o trabalho de compreensão dos gestos de interpretação presentes na constituição de qualquer texto é um trabalho político e, necessariamente, constrói uma ética, pois trabalha com as contradições, com as tensões, enfim, com as diferenças de sentidos. Ou, em outras palavras, trabalha com a contradição entre os processos de administração e institucionalização dos sentidos e com as falhas no ritual da institucionalização desses mesmos sentidos. Não é, portanto, uma questão exterior à Análise do Discurso, ou seja, a ética não se apresenta como algum tipo de cobrança social ou política feita ao trabalho do analista do discurso. Ao contrário, a questão ética se coloca internamente na própria constituição do campo, como tentarei demonstrar.

Mas de que ética(s) estamos falando? E do que se está falando quando se fazem referências a pesquisas em ciências da lingagem e, em particular, em Análise do Discurso?

\section{A ética em questão}

Para iniciar uma discussão sobre as questões formuladas acima parece-me relevante colocar o conceito de 'ética' em suspensão, buscando inventariar algumas de suas várias acepções, inclusive seguindo o percurso crítico elaborado por determinados

\footnotetext{
${ }^{3}$ Pêcheux, 1990.
} 
filósofos. Veremos, então, alguns modos como tal conceito de ética foi produzido e associado ao campo da produção de conhecimento.

Começaremos nosso percurso pelo senso comum dicionarizado, passando depois a uma discussão mais densa dos termos 'ética' e 'moral', na visão de Alain Badiou, para então terminar retornando à discussão sobre 'moral', 'verdade' e 'conhecimento científico' feita por Nietzsche. Tudo isso, é claro, com a finalidade de voltar a discutir questões no âmbito da Análise do Discurso.

\section{No senso comum, na etimologia}

Sem querer esgotar o assunto, parto de uma acepção ampla e disseminada em dicionários da língua portuguesa, segundo a qual a ética, enquanto parte da filosofia, "é responsável pela investigação dos princípios que motivam, distorcem, disciplinam ou orientam o comportamento humano, refletindo especialmente a respeito da essência das normas, valores, prescrições e exortações presentes em qualquer realidade social". ${ }^{4}$ De acordo com essa acepção, e outras assemelhadas, discorrer sobre os princípios éticos implica uma entrada em dois campos: o do comportamento humano e o da essência daquilo que, no convívio social, serviria para regular tal comportamento.

Por extensão, pode-se depreender nesse ponto de vista um entrelaçamento da ética com a moral uma vez que entrelaçar comportamento humano com a essência de normas e valores nada mais é do que retomar, por exemplo, um princípio segundo o qual "o objeto da ética é acima de tudo estabelecer os princípios gerais dos quais os fatos morais são apenas aplicações particulares". ${ }^{5}$ À ética caberia, então, um registro social geral, uma imagem de totalidade, da qual a moral seria parte. Em outras palavras, à ética caberia uma pauta abrangente em relação à qual a moral seria essa ética tomada individualmente.

Outro aspecto ainda a ser ressaltado na definição dada refere-se ao emprego das expressões 'comportamento humano' e 'essência', termos que remetem a um psicologismo e a uma metafísica, respectivamente, de um sujeito responsável por seus atos, dono de suas vontades, dos seus pensamentos e origem de seus dizeres. Um

\footnotetext{
4 Dicionário Honaiss da língua portuguesa.
}

'É. Durkheim, 2003. 
sujeito que é todos e nenhum, o sujeito de direito construído pelo discurso jurídico. Em resumo, materializa-se nos dicionários não especializados um sentido primeiro de ética quase sinônimo de moral e vinculado a uma determinada concepção de sujeito, bem como às ações e intenções subjetivas frente a uma universalidade estável de condutas e valores pressupostos previamente.

Badiou, porém, afirma que em grego "ética refere-se à busca de uma boa 'maneira de ser', ou à sabedoria da ação. Desse modo, a ética é uma parte da filosofia, aquela que coordena a existência prática com a representação do Bem". ${ }^{6}$ Nessa acepção, o que há de mais universalizante em termos de uma definição de ética é essa "sabedoria da ação" relativa à "existência prática", um modo de vida, um modo de ser. Não há referência a condutas específicas, normas, valores previamente postulados, embora a referência a essa existência prática seja relativa às práticas vigentes na sociedade de então. ${ }^{7}$ Embora, de acordo com Badiou, não se encontre aí o aspecto voltado para uma regulação dos costumes, como foi apontado anteriormente, hoje em dia, a ética se encontra vinculada à moral, e moral, lembremos aqui, vem do latim mores, que quer dizer costumes, um hábito ligado às tradições.

Essa superposição entre ética e moral foi se constituindo e se adensando na sociedade capitalista ocidental, uma sociedade juridicamente organizada em torno de direitos e deveres, de tal forma que se tornou parte do cotidiano e ponto de partida (ou de chegada) para o julgamento de diferentes situações. Ao se falar, então, de algum indivíduo X que foi ou não ético em um contexto específico está se fazendo uma avaliação, um julgamento acerca do comportamento de tal indivíduo em nome de uma moral produzida por determinado grupo social - isto é, em nome de determinado costume social e cultural que não foi seguido conforme regras e princípios postulados como legítimos.

Para Badiou, essa moral presente no sentido de ética dá sustentação à ética dos direitos do homem. Está na ordem do dia, segundo o autor, uma defesa intransigente de determinados direitos para determinados homens, direitos esses postulados como naturais, óbvios, evidentes por si sós. Mas como se fundamenta esse Homem de que se fala nessa ética?

\footnotetext{
${ }^{6}$ Badiou, 1995, p. 15.

${ }^{7}$ Mais adiante retomarei Nietzsche em sua crítica a esse conceito de ética oriundo dos gregos.
}

Rua, Campinas, 10:9-22, 2003 
Trata-se do homem enquanto categoria produzida pelo pensamento moderno a partir de Descartes. Com o advento do pensamento cartesiano entra em jogo enquanto categoria filosófica o sujeito racional. Não se trata mais do sujeito platônico, contemplativo, mas sim do sujeito reflexivo, intencional, capaz de julgar e ser julgado por suas práticas quando confrontado com uma lei universal. Em termos dos processos e transformações históricas das relações de força, esse sujeito (cartesiano, enquanto categoria filosófica) é tornado visível no mundo ocidental capitalista: trata-se de um sujeito isolável, identificável, que pode ser responsabilizado e punido pelo que faz e diz. Como foi colocado anteriormente, é pelo discurso jurídico que esse Homem se torna localizável, identificável. Em suma, por 'homem' entende-se naturalmente o indivíduo habitante das cidades, ocidental, do sexo masculino, branco. Em sua crítica, acompanhando Foucault, Althusser e Lacan, Badiou mostra o quanto o discurso ético-humanista produzido pelo pensamento moderno, alicerce de uma sociedade disciplinada e juridicamente controlada, constrói e dissemina no imaginário um apagamento da historicidade que constitui esse sentido de 'homem'.

Mais contemporaneamente, portanto, o dizer ético se encontra constituído por esse modo de organização da sociedade capitalista: está centrado em uma "norma de comentários e opiniões, apoiada em instituições, dispondo de sua própria autoridade". Trata-se de uma moral que visa a regulamentar e tornar permanente, fixando no simbólico, determinadas verdades através da normatização de comentários e opiniões sobre situações históricas, sociais, biotecnológicas e científicas. Não é à toa que a esfera do Direito é, por excelência, na sociedade capitalista, o lugar privilegiado da produção de normatizações de condutas e responsabilidades individuais, e avaliações dessas mesmas condutas e responsabilidades. O sujeito é responsabilizado e penalizado individualmente, em relação a uma ética de direitos e deveres que supostamente ele deveria desde sempre saber de antemão.

Em resumo, o que resulta desses deslizamentos dos sentidos de ética é uma regulação moralizante dos sentidos em direção ao que é dado de antemão como $O$ bom, como $O$ correto. Os discursos que promovem tal regulação são concebidos como verdadeiros,

${ }^{\mathrm{B}}$ Badiou, op. cit. 
da ordem da verdade para o sujeito, verdade colocada como única em função do apagamento do processo histórico que levou à produção de tal verdade.

Para entender melhor do que estamos tratando quando falamos em processo de apagamento histórico, é pertinente destacar, aqui, essa correlação estabelecida indiretamente entre a concepção de sujeito mencionada acima, o conceito de verdade e o de ciência.

\section{Moral, verdade e conhecimento científico}

O que me interessa, nesse ponto, é entender como foi se constituindo no campo da produção de conhecimento um tipo de julgamento estabelecendo a ciência como lugar de produção de verdades. Em outras palavras, a ética enquanto uma moral, suposta na produção de saber, sobretudo na produção de conhecimento sobre a linguagem, também pode ser relacionada a esse humanismo? De que forma?

Também remontando aos gregos, porém puxando outro fio de relações de sentido, na genealogia da moral nietzschiana pode-se ler uma relação entre subjetividade, ética, moral, a construção de verdades e a produção de conhecimento. Em seu percurso interpretativo, Nietzsche mostra que "diversas línguas remetem para uma mesma transformação de conceitos", transformação essa na qual o conceito de bom emana de uma produção discursiva vinculada à nobreza. O conceito de bom, nessa discursividade, adquire um valor moral por aqueles que, detendo o poder, julgavam-se eles próprios possuidores de tal valor. Nessa perspectiva, a ética e a moral aristocrática, cujas raízes históricas se encontram nas relações de poder, eram consideradas como valores imanentes, metafísicos e indicativos de modos de vida." De modo análogo, os conceitos de verdade e de realidade deslizam de seu sentido grego e passam a ser associados à nobreza: "a palavra 'verdadeiro' acaba por designar somente a nobreza de alma."

\footnotetext{
"E essa associação "ocorre em paralelo à que acaba por transformar as idéias de 'comum', 'populacho', 'baixo', na de 'mau'”. (Nietzsche, 1971, p. 24, tradução minha)

${ }^{10}$ Nietzsche, 1971, pp. 26-27 (tradução minha).
} 
A verdade, para Nietzsche, não é uma essência a ser extraída da realidade, algo que existiria por si só esperando ser descoberta. Ao contrário, trata-se de uma construção no simbólico. A verdade é constituída por

um batalhão móvel de metáforas, metonímias, antropomorfismos, enfim, uma soma de relações humanas, que foram enfatizadas poética e retoricamente, transpostas, enfeitadas, e que, após longo uso, parecem a um povo sólidas, canônicas e obrigatórias: as verdades são ilusões, das quais se esqueceu o que são, metáforas que se tornaram gastas e sem força sensível, moedas que perderam sua efígie e agora só entram em consideração como metal, não mais como moedas. ${ }^{11}$

Em outras palavras, a crença na verdade é também uma crença na vontade de verdade, que é uma vontade de certezas. Essa vontade de verdade apaga o caráter subjetivo da produção da verdade, ou seja, impede a compreensão de que a verdade é produzida sócio-historicamente e fixada no simbólico.

Ao estabelecer a genealogia e discutir a historicidade constitutiva desses conceitos, Nietzsche coloca em um mesmo plano crítico a crença na verdade e a sujeição aos valores morais. O sujeito racional acredita na existência de uma verdade, supõe ser possível atingir e conhecer a verdade assim como supõe uma moral do bom e do mau, do certo e do errado encerrada em si mesma.

A produção de conhecimento, por sua vez, se encontra amalgamada com a vontade de verdade e, conseqüentemente, com a moral. No entanto, toda forma de produção de conhecimento é antropomórfica, e por isso "não contém nenhum ponto que seja verdadeiro em si, real e válido universalmente, independente do homem". ${ }^{12}$ Dizendo de outra maneira, o conhecer científico produz verdades sempre contingentes e determinadas pela história das relações de força; por esse motivo, não tem uma neutralidade em si, não é desinteressado. Encontra-se em Nietzsche uma crítica contundente ao positivismo na ciência, ou seja, uma crítica nessa crença na verdade dos dados, dos fenômenos. $\mathrm{O}$ conhecimento, da mesma forma que os valores e a verdade, é constituído historicamente

${ }^{11} I d ., 1991$, p. 24.

${ }^{12}$ Id., Escritos póstumos, apud Machado, 1984, p. 116. 
e, portanto, é mutável e dependente das relações de poder e dos valores instituídos. "Conhecer não é explicar, é interpretar", ${ }^{13}$ diz Nietzsche. E não há uma única interpretação do mundo, nem há uma que seja mais legítima: "não existem fatos, mas apenas interpretações." ${ }^{14}$

Em sua apresentação do pensamento nietzschiano, Roberto Machado dirá que "a vontade de verdade é a crença, que funda a ciência, de que nada mais é necessário do que o verdadeiro. Necessidade não de que algo seja verdadeiro, mas de que seja tido como verdadeiro". ${ }^{15}$ E esse é o elo que liga a ciência à moral: a vontade de verdade e a necessidade de certezas.

Em síntese, há um imaginário historicamente constituído impregnando o saber científico que apaga, no senso comum e em muitas vertentes do pensamento científico, o fato de que o conhecimento produzido é fruto de um gesto de interpretação, ou seja, é fruto das condições materiais de existência de um sujeito determinado por sua inserção na história e na memória da produção desse mesmo conhecimento. Memória entendida aqui como um vasto arquivo das histórias de leituras constitutivas do objeto em questão. Um arquivo, diga-se de passagem, que inclui predominantemente as leituras legitimadas e consideradas verdadeiras bem como as que foram recalcadas em função de uma legitimação ideológica.

Em termos da circulação das formações imaginárias, o conhecimento científico se constitui como um universo de discursos logicamente estabilizados, ${ }^{16}$ discursos que se mostram como produtores de verdades.

\section{A ética no fazer discursivo}

Transportando-nos para o nosso tema, é possível pensar o quanto o campo das ciências humanas, e mais especialmente o campo da ciência da linguagem, vem pagando um pesado tributo por estar inserido na tradição de conhecimento científico descrita acima.

Analisando, em vários artigos, a conjuntura na qual as ciências sociais e humanas se encontravam entre os anos 1960 e 1980 e considerando, sobretudo, o papel dos

\footnotetext{
${ }^{13}$ Nietzsche, Escritos póstumos, apud Machado, 1984, p. 108.

${ }^{14}$ Ibid.

15 Ibid, 1984, p. 84.

${ }^{16}$ Expressão de Pêcheux, 1999.
} 
instrumentos científicos e das técnicas nesse campo, Pêcheux se detém em discutir a situação da lingüística e o contexto epistemológico no qual a Análise do Discurso se desenvolve. ${ }^{17}$ Sendo bastante cuidadoso e meticuloso ao criticar o formalismo na lingüística e o conteudismo nas ciências sociais, Pêcheux abre caminho para a constituição da análise do discurso como um lugar em que uma crítica se exerça internamente e de modo permanente. Essa direção de trabalho, como veremos, após uma breve apresentação do campo de trabalho da Análise do Discurso, produz efeitos que trazem a ética para dentro da própria $\mathrm{AD}$ e a tornam uma questão de responsabilidade porque o que está em jogo é uma prática de compreensão do engendramento das filiações de sentido.

Para exercer tal crítica, Pêcheux propõe uma mudança de terreno que, com a intervenção da filosofia materialista, coloca em prática a crítica ao humanismo, ao ahistoricismo e à concepção de língua então vigentes. Para Pêcheux, tal intervenção "consiste em abrir campos de questões", fazendo a ciência da linguagem estabelecer relações no domínio das ciências das formações sociais.

Recusando o idealismo em vigor nas ciências humanas (em especial na psicologia) e colocando em discussão o movimento estruturalista, Pêcheux vai assinalar que o sujeito, enquanto constituído pela linguagem, não é causa ou origem de si mesmo. De acordo com P. Henry, assim como vários intelectuais de sua época, Pêcheux objetiva "desfazerse do sujeito transcendental em qualquer de suas formas". ${ }^{18}$ Nesse ponto, vale dizer, a releitura da lingüística saussureana e de seus desdobramentos foi crucial para o desenvolvimento teórico tanto da psicanálise quanto do materialismo histórico e da Análise do Discurso: a recusa ao idealismo presente na concepção de sujeito soma-se à recusa de uma concepção transparente de linguagem como instrumento de comunicação de informações.

${ }^{17}$ Pêcheux, 1969, 1999, dentre outros textos. No caso específico da lingüística, são duas as tendências presentes contraditoriamente, ambas apresentando desdobramentos e formas intermediárias. Em uma, a linguística se constitui como uma ciência que toma a língua como fato social: é a tendência chamada de sociologista, que descreve a dispersão das variantes lingüísticas e supõe o sujeito falante em sua forma social empírica. Na outra, nomeada de logicista, ou formalista, o trabalho teórico incide na construção de gramáticas que possam dar conta das relaçōes entre linguagem e pensamento. A Análise do Discurso, é importante dizer, não é proposta como uma terceira tendência.

${ }^{18}$ P. Henry, 1990.

Rua, Campinas, 10: 9-22, 2004 
A Análise do Discurso, que tem no discurso seu objeto de análise, concebe de modo diferente da lingüística os conceitos de sujeito, língua e história. Para tanto, sua constituição teórica agrega três diferentes regiões do saber: o materialismo histórico, entendido como teoria das formações sociais e suas transformações; a lingüística, enquanto teoria dos processos de enunciação; e a semântica discursiva, como a teoria dos processos materiais de produção da significação. Essas três regiões são atravessadas por uma teoria do sujeito de base psicanalítica.

Para a Análise do Discurso, portanto, o sujeito não corresponde a um indivíduo empírico, cuja descrição a sociologia e a psicologia costumam fazer. Não se trata, tampouco, do sujeito cartesiano, dono de suas vontades, de suas certezas e do seu dizer. Trata-se do sujeito estruturalmente dividido, assujeitado ao ideológico. Nessa concepção, o sujeito tanto é constituído pelo simbólico, enquanto sistema significante sujeito a falhas, quanto materializa nesse mesmo simbólico as falhas e os equívocos que o estruturam.

Para Pêcheux, em sua direção teórica da relação entre o inconsciente e a ideologia, o processo de constituição do sujeito pela linguagem não se realiza fora do históricoideológico. Trazendo o ponto de vista do materialismo histórico, Pêcheux trabalha a história não "como puro efeito imaginário", mas como lugar contraditório em que na língua se materializam tanto as repetições quanto os equívocos, ou seja, os pontos que afetam a univocidade lingüística do sujeito, levando o sujeito ao encontro do real histórico. ${ }^{19}$

$\mathrm{Na}$ constituição do sujeito pela linguagem, encontra-se recalcado o processo de interpelação ideológica e de divisão inconsciente. Para ser sujeito do que diz, o sujeito é afetado por dois esquecimentos: de que não é origem do dizer e de que não controla totalmente o que diz. Encontra-se recalcado para o sujeito seu assujeitamento à formação discursiva que o domina, ou seja, o sujeito não percebe que seu dizer se encontra historicamente circunscrito às redes de paráfrases, substituições metafóricas e encadeamentos constitutivos dos processos de produção dos sentidos inerentes às formações discursivas que o constituíram e que garantem um efeito de literalidade para as representações imaginárias.

\footnotetext{
${ }^{19}$ Palavras de Pêcheux referindo-se a Milner: "A irrupção do equívoco", diz Pêcheux, "afeta o real da história (...), o equívoco aparece como o ponto onde o impossível (lingüístico) vem se conjugar à contradição (histórica)." (Pêcheux, 1981, p. 32 e mais adiante p. 62)
}

Rua, Campinas, 10:9-22, 2003 
Desse ponto de vista, o sujeito é uma posição material lingüístico-histórica produzida em meio ao jogo de contradições e tensões sócio-ideológicas. O que é ponto incontornável de análise são as posições discursivas ocupadas pelo sujeito para ser sujeito do que diz em condições histórico-ideológicas determinadas. Um dizer inscrito na estrutura do sujeito e na ideologia, isto é, um dizer com o qual o sujeito se identifica sem ter absoluto domínio do processo que o leva a ter tal identificação.

Assim, em uma dada análise, busca-se compreender o modo de produção de sentidos resultante das posições discursivas de sujeito constituídas na materialidade textual. Não se considera um conteúdo ou um significado existente a priori, nem uma intencionalidade manifesta do sujeito ao dizer o que disse. Como nos lembra Pêcheux, "ninguém pode estar seguro de saber do que fala". ${ }^{20}$ Por isso, o que interessa é verificar como foram produzidos os sentidos e que efeitos daí decorrem. Não se pode esquecer, aqui, que sentido é relação a, ou seja, resulta de filiações históricas a interpretações muitas vezes esquecidas, mas que nem por isso deixam de produzir efeitos na memória. Em função desse posicionamento crítico internalizado nos procedimentos de análise discursiva, entende-se que um dizer sempre pode ter mais de um sentido e que tais sentidos, para serem compreendidos, precisam ser analisados em função de sua inserção em uma memória histórica e ideológica.

Numa proposta de análise dessa natureza, não cabe ao analista de discurso avaliar se uma determinada matéria jornalística está certa ou errada, se uma determinada campanha política ou publicitária é adequada ou inadequada, se os direitos e deveres estão ou não sendo cumpridos conforme a moral social vigente ou passada. Em resumo, não cabe ao analista julgar a veracidade ou falsidade de qualquer discurso ou desvelar retóricas entrelinhas capciosas. Em outras palavras, se para um analista de discurso "o sentido sempre pode ser outro", tal afirmação o remete para o caráter material do sentido, para sua relação com as condições históricas em que foi produzido. Um analista de discurso se perguntará sempre que outros modos de dizer seriam possíveis, que paráfrases de fato foram produzidas e quais poderiam vir a ser. Contudo ele sabe que por mais que um sentido possa ser outro, ele nunca será qualquer outro sentido. Seus limites são produzidos na historicidade que os constitui.

${ }^{20}$ Pêcheux, apud Orlandi, 2002, p. 49. 
Ao contrário, e dizendo junto com Pêcheux, para a Análise do Discurso "é suficiente colocar suas próprias problemáticas e procedimentos: a questão crucial é construir interpretações sem jamais neutralizá-las nem no 'não-importa-o-quê' de um discurso sobre o discurso, nem em um espaço lógico estabilizado com pretensão universal". ${ }^{21}$

Por fim, para fazer Análise do Discurso, para ocupar uma posição analítica sobre os processos discursivos de produção de sentidos, é necessário que o próprio analista se reconheça em seu assujeitamento ideológico e em sua divisão inconsciente. É imprescindível, portanto, que o analista não perca de vista o paradoxo que constitui seu trabalho: ele também é afetado pelo inconsciente e pela ideologia. Desta forma, reinterrogando seus pressupostos incessantemente, um analista de discurso não supõe que sua análise seja A Análise, portadora de única verdade.

E é aí que reside, no meu entender, o caráter ético que constitui o investimento discursivo: a compreensão dos processos de produção de sentidos, por investigar as interpretações produzidas, hegemônicas ou não, por incidir na relação da língua com a história, por considerar o sujeito dividido, está sempre retornando sobre seu papel no trabalho de interpretação. E esse é um papel ético e de responsabilidade.

\section{Abstract}

This text opens to discussion the concept of ethics, its interface with linguistic research and specially with the theoretical and methodological framework from Discourse Analysis.

\section{Referências bibliográficas}

BADIOU, A. Ética: um ensaio sobre a consciência do mal. Rio de Janeiro: RélumeDumará, 1995.

CHALMERS, A. O que é a ciência afinal? São Paulo: Brasiliense, 1993.

DURKHEIM, É. Ética e sociologia da moral. São Paulo: Landy Livraria Editora, 2003.

HENRY, P. A ferramenta imperfeita. Campinas: Ed. da Unicamp, 1990.

MACHADO, R. Nietzsche e a verdade. Rio de Janeiro: Rocco, 1984.

NIETZSCHE, F. La généalogie de la morale. Paris: Gallimard, 1971.

${ }^{21}$ Pêcheux, (1983) 1999, p. 16. 
Obras incompletas. Coleção Os Pensadores. São Paulo: Editora Nova Cultural, 1991.

ORLANDI, E. Ética e política das línguas. In: Orlandi, E. Língua e conhecimento linguiístico. São Paulo: Cortez Editora, 2002, p. 75-100.

PAIVA, R. Ética, cidadania e imprensa. Rio de Janeiro: Mauad, 2002.

PÊCHEUX, M. (1983). Sobre os contextos epistemológicos da análise de discurso. In: Escritos n. 4. Campinas: Labeurb-Nudecri-Unicamp, 1999.

- Discurso: estrutura ou acontecimento. Campinas: Pontes, 1994.

- Les sciences humaines et le 'moment actuel'. In: La Pensée, 143, 1969.

. (sous le pseudonyme de Thomas Herbert). Réflexions sur la situation théorique des sciences sociales et, spécialement, de la psychologie sociale. In: Cahiers pour l'analyse, 2, 1966.

. e GADET, F. Há uma via para a lingüística fora do logicismo e do sociologismo? In: Escritos n. 3. Campinas: Labeurb-Nudecri-Unicamp, 1998. 